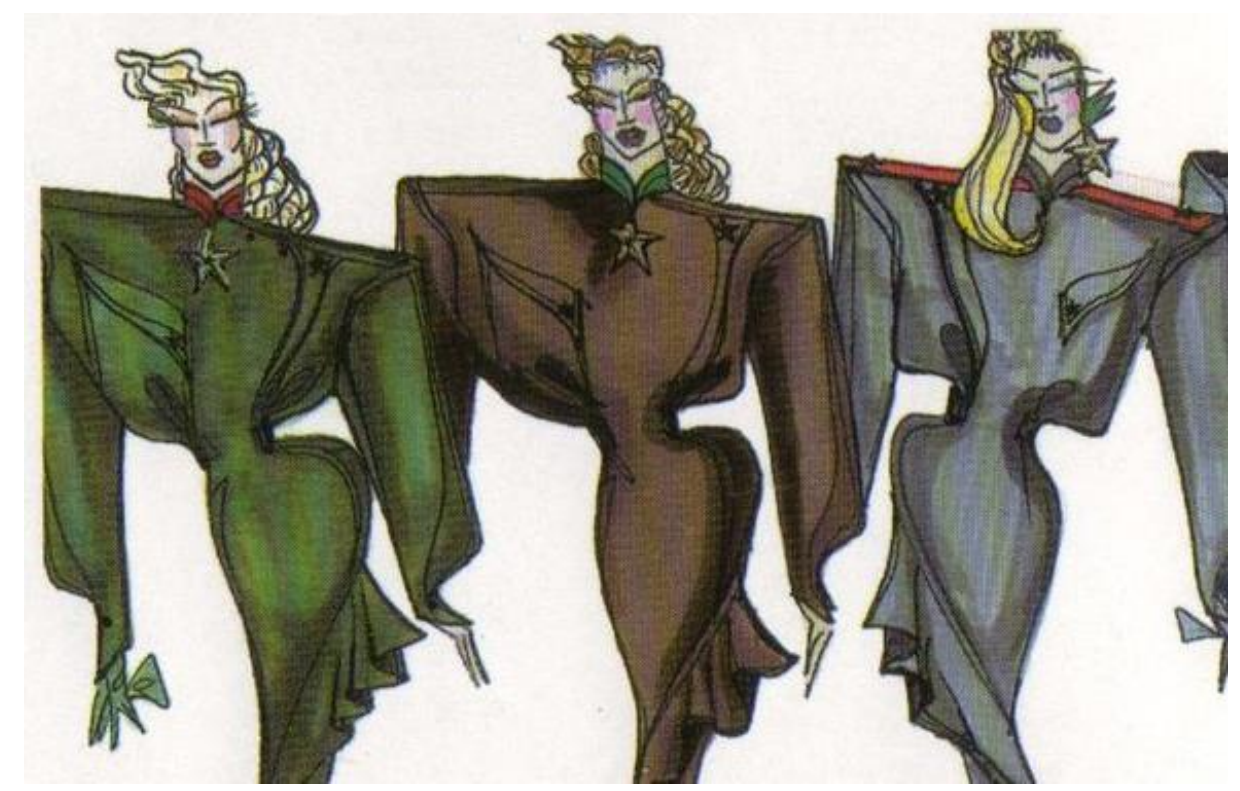

\title{
Construindo ombros fortes: A roupa ressignificando o corpo feminino
}

Building strong shoulders: how clothes can resignify the female body

\section{Leonardo Perez ${ }^{*}$ \\ Luzmara Curcino** $^{* *}$}

\section{Resumo:}

Neste trabalho, baseados nas reflexões de Jean-Jacques Courtine sobre o corpo como forma de manifestação de discursos, construído como objeto simbólico sobre o qual atuam as injunções da cultura e da história, buscaremos analisar como a moda, especialmente no que concerne ao vestuário, pode ressignificar o valor simbólico do corpo. Assim, apoiados nos estudos da Análise do Discurso de linha francesa, pretendemos analisar - a partir de imagens veiculadas em revistas de moda dos anos 1980 - como se deu a circulação de discursos sobre a mulher, sobre o poder, manifestos por diversas materialidades, entre elas aquela de delineação de uma silhueta antes restrita aos homens e que possibilitou uma ressignificação do corpo feminino, buscando em Margaret Thatcher um marco desse acontecimento discursivo.

Palavras-chave: Análise do discurso; Corpo; Moda

\section{Abstract:}

In this paper, based on the reflections of Jean-Jacques Courtine upon the body as a form of manifestation of discourses, like a symbolic object on which act the injunctions of the culture and the history, we will analyze, how fashion, especially with regard to clothing, can reframe the symbolic value of the body, impose ways of looking and assign meanings. In addition to the reflections upon the body, we based our research in Discourse Analysis of French line. Thus, we intend to analyze- from images conveyed in fashion magazines of the 1980s - how was the symbolic appropriation by a silhouette of women formerly limited to men and that provided a resignification of the female body, seeking a benchmark in Margaret Thatcher of this discursive event.

Keywords: Discourse Analysis, body, fashion

\footnotetext{
* Mestre em Linguística pelo Programa de Pós-Graduação em Linguística (PPGL) da UFSCar. Endereço: Rua João Carbonari Jr, 214 ap. 62 bloco 30 - Res. Anchieta Jundiaí - SP CEP 13410-705. E-mail: leonardoperezleo@gmail.co

${ }^{* *}$ Professora adjunta do departamento de Letras edo Programa de Pós-Graduação em Linguística (PPGL) da UFSCar, e coordenadora do LIRE (Laboratório de estudos Interdisciplinares das Representações do Leitor brasileiro contemporâneo).
} 


\section{Introdução}

Tendo em vista o interesse bastante acentuado pelo corpo, como objeto de investigação histórica, nos dias de hoje, assim como objeto dos estudos da linguagem, uma vez que é considerado como signo ou como portador de diversos signos, empreenderemos aqui uma análise de viés discursivo acerca da roupa e da sobreposição simbólica da mesma em relação ao corpo que, por meio dela, é afetado e por ela "fala".

A vestimenta, que perdeu sua função fundamental de proteção do corpo, passa a representar uma extensão do mesmo, ressignificando-o. Neste trabalho, e considerando essa dimensão simbólica da roupa em relação ao corpo, voltaremos nosso olhar para uma parte específica desse corpo: os ombros que, ao serem encobertos por uma camada de espuma contida no interior de determinadas roupas, as ombreiras, apresentam-se como indício de um uso simbólico do poder há muito explorado e também há muito empregado como um atributo próprio e exclusivo de roupas masculinas.

Para essa discussão sobre o corpo como linguagem e de sua análise de um viés discursivo, o trabalho de Jean-Jacques Courtine é incontornável. Ele “[...] postula [...] a necessidade de alargar o enfoque da $\mathrm{AD}$ [uma vez que] o verbo não podia mais ser dissociado do corpo, do rosto, dos gestos e das imagens [...]” (PIOVEZANI, 2009, p.35).

Ao analisar o discurso político, Courtine sente a necessidade de discutir as questões em torno do rosto. $\mathrm{O}$ que deveria abranger o período contemporâneo e o campo político acabou gerando um completo estudo sobre "as práticas e representações do rosto" ao longo da história (PIOVEZANI, 2009, p. 35). Em 1988, ele lança em conjunto com Claudine Haroche a História do rosto: Exprimir e calar as suas emoções (do século XVI ao início do século XIX), livro no qual se "insere um princípio antropológico em uma história de longa duração na tentativa de compreender uma ambivalência fundamental em torno da expressividade moderna: a injunção a expressarse e o dever de controlar a expressão" (PIOVEZANI, 2009, p.36).

Seguindo com seus estudos, Courtine, nos anos 90, volta seu olhar para o corpo. Interesse este que resulta na publicação da obra História do Corpo (2005 e 2006), em três volumes, organizada em conjunto com Alain Courbain e Georges Vigarello.

Ao corpo, a partir das concepções greco-romanas até o final do século XIX, eram relacionadas as noções de pecado e impureza, e o mesmo era concebido separadamente da alma. Já no século XX, passa a ser concebido por sua relação de 
interação inseparável com o sujeito, ou seja, o interno e o externo, o corpo e a alma, o corpo e a dimensão sensível estão interligados (COURTINE, 2008).

Para Courtine, o século XX “inventou teoricamente o corpo" (COURTINE, 2008, p.7). Essa invenção se deu em três momentos históricos fundamentais: a invenção da psicanálise por Freud ao decifrar a conversão histérica e preconizar o inconsciente como linguagem que "fala através do corpo" (COURTINE, 2008, p.7); a difusão da noção de corpo como pivô principal do mundo, promovendo diversas abordagens filosóficas, da fenomenologia por Maurice Merleau-Ponty ao existencialismo por JeanPaul Sartre; e, finalmente, a descoberta do corpo no campo da antropologia por Marcel Mauss que, no período da Primeira Guerra Mundial (1914-1918), “[...] observou a infantaria britânica desfilar num passo diferente do passo dos franceses e cavar buracos de maneira singular" (COURTINE, 2008, p.8). Assim "o corpo foi ligado ao inconsciente, amarrado ao sujeito e inserido nas formas sociais da cultura" (COURTINE, 2008, p.8).

Mas ainda faltava ao corpo outro obstáculo científico a superar, "a obsessão linguística do estruturalismo" (COURTINE, 2008, p.8), que enterrava "a questão do corpo com a do sujeito e suas "ilusões"' (COURTINE, 2008, p.8). Mas as coisas mudaram assim que o corpo começou a desempenhar importante papel nos movimentos individualistas e pela igualdade.

Assim, após esses movimentos,

\section{[...] as lutas políticas, as aspirações individuais colocaram o corpo no coração dos debates culturais, transformaram profundamente a sua existência como objeto de pensamento. Ele carrega, desde então, as marcas de gênero, de classe ou de origem, e estas não podem ser mais apagadas. (COURTINE, 2008, p.9)}

Com base nos estudos desenvolvidos por Courtine a respeito do corpo como objeto de discurso, realizaremos aqui algumas reflexões acerca da moda no vestuário, tendo em vista que o homem superou, em relação à roupa, sua função primaz de proteger o corpo emprestando-lhe outros significados, em seu papel de segunda pele. Segundo Paul Schilder (1980), psiquiatra austríaco que desenvolveu estudos a respeito da imagem corporal, "as roupas fazem parte do esquema corporal, ganham o mesmo sentido das partes do corpo e podem ter o mesmo significado simbólico destas" (SCHILDER, 1980, p.177).

Visamos, portanto, neste breve artigo, discutir a função simbólica dessa roupa que se agrega ao corpo e produz significados para o mesmo e em conjunto com ele. 
Mapearemos, especificamente, o uso de ombreiras pelas mulheres e as representações desse objeto ao longo da história, que produziram sentidos no que concerne ao corpo feminino que não as portava e que, num dado momento, se apropria desse objeto.

\section{O corpo feminino ressignificado: uma breve análise}

Após um longo período histórico de excessos e abusos, de uma roupa rígida e incômoda, Paul Poiret, precursor dos estilistas como os conhecemos hoje, cria a silhueta feminina do século XX (LURIE, 1997), com formas que davam mais mobilidade às mulheres, eliminando os espartilhos e o excesso de roupas íntimas. O predomínio da concepção de Poiret chega ao fim nos anos 20 com a entrada de Gabrielle Chanel na cena da moda (KÖHLER, 1983). Esta, por sua vez, "empresta" do guarda-roupa masculino peças que logo ganhariam a preferência das mulheres consumidoras de moda, tais como o tailleur $^{l}$, que já apresentava ombros sutilmente marcados, mas ainda privilegiava a fluidez frente à rigidez dos ombros do terno masculino. Posteriormente, as roupas da época da guerra refletiram o racionamento de tecidos que foi estabelecido em 1941 e, assim, ganharam um apelo masculino ainda maior, recebendo grande influência militar, evidenciando agora seu caráter utilitário (VEILLON, 2004). Os ombros eram quadrados, a forma reta e o corte masculino imitava o corte das fardas: a moda estava militarizada. No pós-guerra aconteceria o inverso, com o fim do racionamento, chegara o momento de esquecer a guerra e, então, Christian Dior cria vestidos e saias com até 30 metros de tecido: o New Look, a volta da feminilidade, a silhueta feminina é então acentuada e exagerada (BAUDOT, 2002).

As décadas de 60 e 70 também têm um papel importante na história da moda, uma vez que as roupas acompanham os movimentos culturais e de liberação sexual. Essa liberação "oferecia a possibilidade de desafiar uma ordem social opressiva e foi um elemento crucial para a luta pela mudança social" (WEEKS, 2000, p.30). Essas mudanças, juntamente com o advento da pílula anticoncepcional, foram algumas das grandes responsáveis pela inserção efetiva da mulher no mercado de trabalho, em cargos antes apenas ocupados por homens (VALCÁRCEL, 2005).

\footnotetext{
${ }^{1}$ Conjunto feminino de saia e casaco ou calça e casaco, muito usado pelas executivas. O traje começou a ser adotado em 1880, mas foi popularizado pela estilista Coco Chanel, na década de 1950. Ela simplificou o corte da roupa, que virou o uniforme da mulher contemporânea. Disponível em: <http://manequim.abril.com.br/moda/dicionario-da-moda/?bl_=t>. Consulta em 30 de Jan, 2012.
} 
Neste contexto histórico, Margareth Thatcher torna-se a primeira mulher a ser primeira-ministra do Reino Unido e adota como marca registrada em sua vestimenta os tailleurs, mas que, desta vez, chamam a atenção para uma parte do corpo ainda pouco explorada pela moda feminina: os ombros. Levemente marcados pela moda durante a guerra, rememorado pelo smoking, vestimenta emprestada do guarda-roupa masculino, de Yves Saint Laurent nos anos 60, aparece de forma expressiva na década de 80, proporcionando uma modificação visualmente perceptível na silhueta feminina. Thatcher, uma das únicas representantes do gênero feminino entre os estadistas majoritariamente do gênero masculino, e exercendo um cargo de grande autoridade no contexto mundial, encontra na ampliação dos ombros, através da roupa, um símbolo de poder.

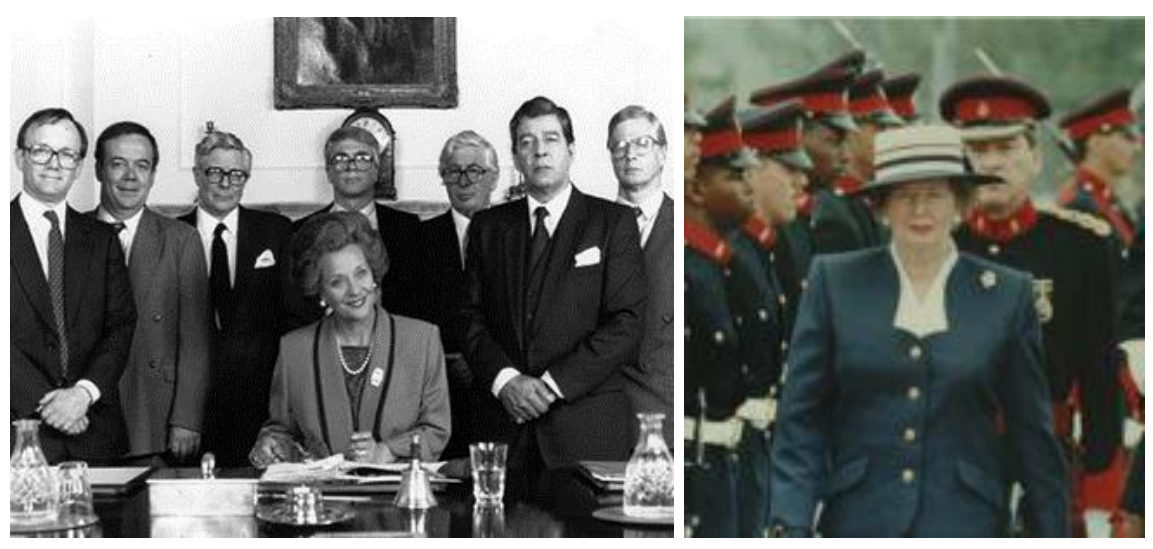

Figura 1: Fotos de Margaret Thatcher (Fonte The Guardian²)

Algum tempo depois, nas passarelas de Milão, o desfile do estilista italiano Giorgio Armani apresentaria ternos femininos com ombros exagerados, peças que rapidamente foram aderidas pelas executivas estadunidenses que iniciavam suas carreiras no mercado financeiro norte-americano e desejavam impor-se frente aos executivos do gênero masculino.

As ombreiras, originalmente um acessório componente das fardas militares, usadas inicialmente para a proteção e, posteriormente para caracterizar os oficiais de alta patente (VEILLON, 2004), obtêm de suas origens seu significado simbólico: o poder, uma vez que remetem ao universo e ao corpo masculino.

Dos campos de batalha, as ombreiras foram adaptadas para o uso diário, quando passaram a fazer parte da configuração do terno masculino. Historicamente, o terno

\footnotetext{
${ }^{2}$ Disponível em: <http://www.guardian.co.uk/politics/2012/mar/05/lord-st-john-fawsley-character? newsfeed=true $>$. Consultado em: 31 de Jan. de 2012 .
} 
surgiu com a Queda da Bastilha, em 1789, pois usar roupas luxuosas, o padrão para os homens da época, poderia resultar em morte. A mando de Luís XVI e disseminada a partir da burguesia ascendente inglesa, a simplicidade e a praticidade foram adotadas nos trajes masculinos, na Europa - e principalmente na Inglaterra - conhecida como a terra da liberdade e, assim, repentinamente não havia mais casacos bordados, tecidos brocados, perucas ou cabelos empoados (LAVER, 1989). Aos poucos, o vestuário masculino passou cada vez mais a apoiar-se nos valores da discrição, resultando em uma espécie de imobilismo e rigidez na moda para homens, contrária às constantes variações do vestuário feminino. Assim, mantendo a composição das roupas da corte francesa, paletó, calça e colete, mas sofrendo influências militares, como a inserção das ombreiras e das gravatas, os ternos passaram a dominar o guarda-roupa masculino.

Ligadas ao universo masculino (virilidade) e militar, as ombreiras passaram a ser uma afirmação de poder e, assim que possível, foram requisitadas pelas mulheres para que pudessem demarcar seu lugar social, principalmente no mercado de trabalho.

O corpo masculino, em uma definição própria do universo da moda, é chamado de "triângulo invertido", pois possui, em geral, o ombro mais largo do que o quadril. O terno com ombreiras é uma das formas de melhor demarcar essa característica.

Ao adotar as ombreiras, o corpo feminino através da roupa, reivindica essa característica, própria do masculino, para ressignificar seu corpo:

Se o homem não existe senão através das formas corporais que o colocam no
mundo, toda modificação de sua forma engaja uma outra definição de sua
humanidade. Se as fronteiras do homem são traçadas pela carne que o
compõe, recortar ou acrescentar nele outros componentes traz o risco de
alterar a identidade pessoal que é a sua e de perturbar os sinais que, aos olhos
dos outros, lhe concernem (LE BRETON, 1995, p. 64-65).

Margareth Thatcher, ao utilizar as ombreiras nos anos 80, ressignifica seu corpo, aproximando-o do masculino para, assim, denotar poder, logo, esse mesmo objeto passou a ser adotado pelas mulheres que buscavam a inserção no mercado de trabalho. Schilder (1999) observa que qualquer objeto, inclusive as roupas, que se conecte ao corpo passa a incorporar-se a ele. Assim, ao aderirem às ombreiras, essas mulheres davam ao corpo um novo formato, mais masculino e, portanto, melhor aceito em ambientes sociais até então dominado pelos homens. Courtine, em seu texto $O s$ stakhanovistas do narcisismo (1995), ao falar sobre a explosão da cultura do corpo

\footnotetext{
${ }^{3}$ Definição disponível em http://oficinadeestilo.blog.tagnclick.com.br/?tag=ombreiras Consulta em: $30 / 01 / 2012$
} 
musculoso na década de 1980, fala de "mulheres-mutantes, cujo sexo se apaga sob a capa de músculos" (COURTINE, 1995, p.83), assim, a utilização das ombreiras pode ser percebida como uma busca por esse corpo musculoso e, consequentemente, da "[...] potência corporal viril como um signo essencial de beleza e de poder" (COURTINE, 1995, p.91).

Essa modificação, portanto, no vestir feminino foi absorvida pelos estilistas e pelas grandes marcas e as imagens que ligavam o poder ao uso de roupas com ombreiras começaram a emergir nos mais variados meios, como atestam os exemplos abaixo:

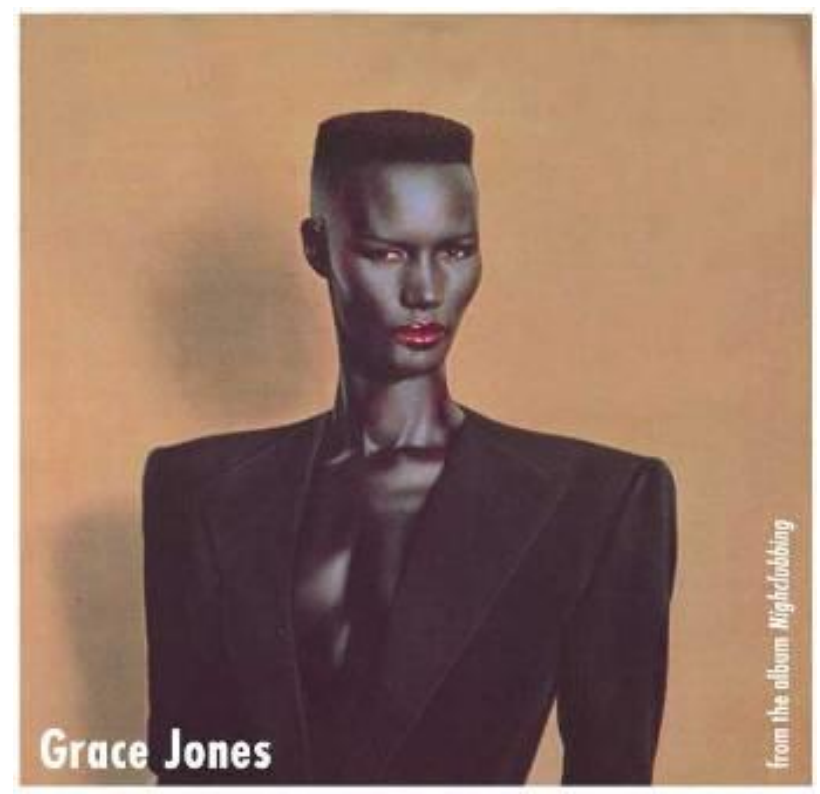

Figura 2: capa do disco Nightclubbing, 1981

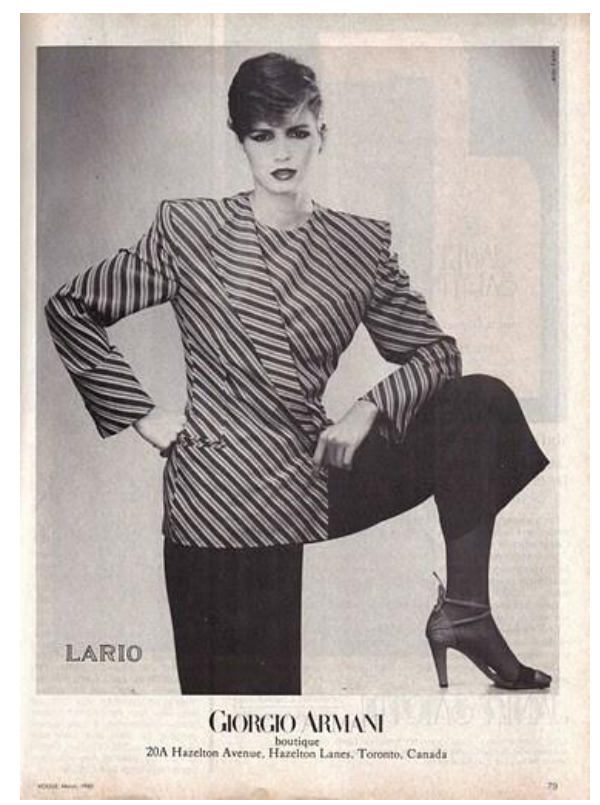

Figura 3: publicidade da marca Giorgio Armani, 1982 
A Figura $2^{4}$ trata-se da capa do disco da cantora Grace Jones, usando um blazer com ombreiras avantajadas. A cantora, que atingiu grande sucesso na década de 80, ficou conhecida por sua estética extremamente andrógina. Na capa de seu disco Nightclubbing (1981), a artista aparece com um blazer de ombreiras na cor preta, tipicamente masculino, mas ao mesmo tempo sua boca apresenta uma coloração fortemente vermelha, uma característica tipicamente feminina. Sua figura domina praticamente toda a imagem e seus cabelos possuem um corte militar, extremamente curto. Todas estas características intensificam seu apelo poderoso, a imposição de sua figura.

Na Figura $3^{5}$, uma campanha publicitária da grife italiana Giorgio Armani, do ano de 1982, a modelo também usa um blazer de ombreiras. Sua figura se impõe e adota uma postura tipicamente masculina, sua perna esquerda encontra-se dobrada e apoiada numa superfície mais alta. Seus cabelos são cortados no estilo masculino, mas ainda possui características que a feminilizam, como a maquiagem e os sapatos. Nas duas imagens as modelos apresentam um olhar sério, não sorriem, constituindo um ar de austeridade, seriedade, retidão, reforçado pela exploração dos traços geométricos muito marcados em ambas as imagens.

Embora menos marcadas, do ponto de vista geométrico, esses índices da austeridade, retidão do corpo que posa para fotos, na imagem a seguir, pertencente a um editorial de moda da revista Vogue América, também da década de 80, em hipotética situação não posada, a modelo apresenta uma roupa com ombreiras fartas, num casaco com formas austeras que ainda sustentam essa proximidade com a vestimenta masculina:

\footnotetext{
${ }^{4}$ A imagem da capa do disco está disponível em: <http://thelonesomepiker.blogspot.com.br/2011/02/ lonesome-grace.html>. Consultada em: 30 de Jan. de 2012.

5 A imagem da campanha publicitária da grife Giorgio Armani está disponível em: <http://www.fashionindie.com/post/vintage-ads-gia-for-armani>. Consulta em: 30 de Jan. de 2012.
} 


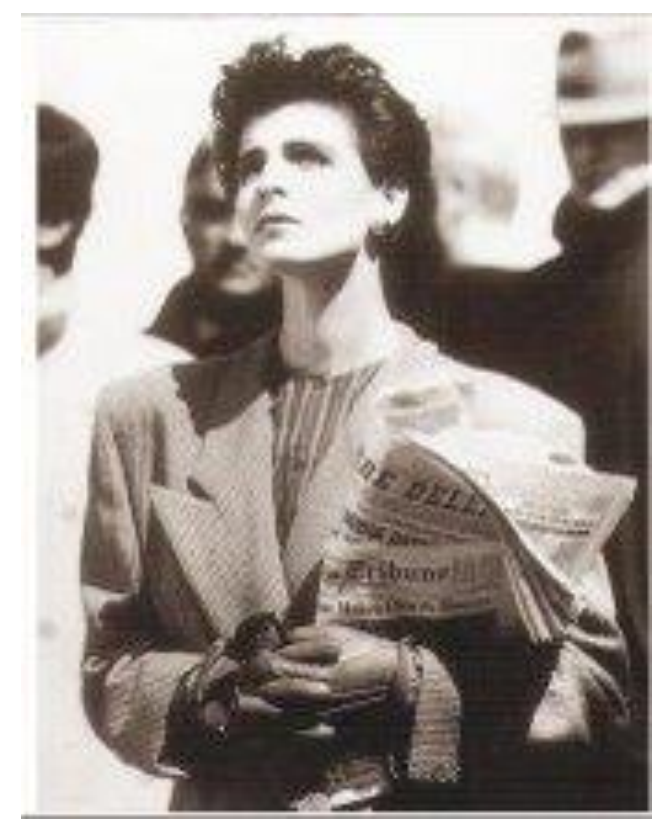

Figura 4: editorial da revista Vogue, 1982

Na Figura $4^{6}$, a modelo também utiliza um blazer masculino de ombreiras, não sorri, carrega nos braços jornais. Seu corte de cabelo é curto. Atrás da modelo observamos apenas a presença masculina, trata-se de uma mulher ocupando uma posição entre homens, provavelmente alguém que não se dedica a profissões socialmente cristalizadas como femininas. $\mathrm{O}$ editorial de moda desta revista feminina constrói uma nova posição para a mulher, não mais restrita ao lar, mas inserida no espaço externo das ruas. Podemos aqui, fazer um paralelo com a análise de Courtine sobre a prática do body-building ${ }^{7}$, que, segundo o autor, “[...] são particularmente identificadas com o 'estilo de vida' da camada social que se tornou o emblema dos anos 80: os yuppies. [...] 'jovens profisionais urbanos' ávidos pela auto-realização através do sucesso material" (COURTINE, 1995, p.85). Assim, a imagem da revista Vogue relaciona a modelo a essa camada social, os yuppies, que por sua vez tem uma relação direta com o culto ao corpo musculoso, portanto, a utilização das ombreiras mostram o interesse de modificação corporal em busca de signos de poder.

Para melhor constatar essa relação, da roupa com ombreiras e o poder que proporcionaria às mulheres, analisamos capas e matérias de revistas femininas que circularam na década de 80 e que entrecruzam enunciados verbais com os imagéticos, fazendo emergir discursos sobre a mulher e o poder.

\footnotetext{
${ }^{6}$ Imagem disponível em: < http://tudopelamoda.blogspot.com.br/2009_02_01_archive.html>. Consultada em: 31 de Jan. de 2012.

${ }^{7}$ Para Courtine, o body-building participa plenamente da cultura do músculo, é um elemento central da cultura do corpo, aumentando-o de modo literal, até seu extremo.
} 
A primeira imagem analisada trata-se da capa da revista Nova de janeiro de 1980:

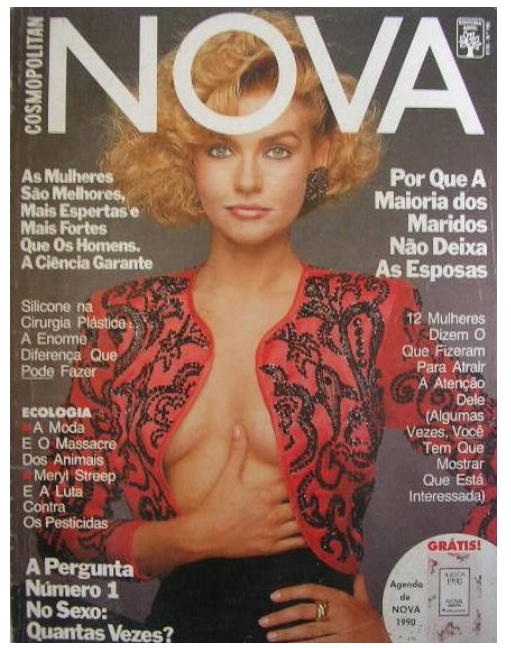

Figura 5: Capa da Revista Nova, janeiro de 1980

$\mathrm{Na}$ imagem ${ }^{8}$ a modelo utiliza um casaqueto bordado com ombreiras, por se tratar de uma revista que se define como "a revista da mulher cheia de atitude" sua abordagem principal é o relacionamento amoroso-sexual entre parceiros heterossexuais. Outro traço característico dessa publicação é trazer frequentemente em suas capas mulheres seminuas, o que representa, de modo ambíguo, o poder da mulher em relação a seu próprio corpo e o poder de sedução em relação ao universo masculino, assim como a revisitação de sua imagem como objeto de desejo. Courtine nos lembra que "A exposição pública de seus corpos permite a algumas mulheres uma maior mobilidade social e profissional. O corpo [...] vai desempenhar um papel essencial no imaginário de promoção individual.” (COURTINE, 1995, p.98). Nesta edição, de janeiro de 1980, a modelo também não utiliza uma blusa por baixo do casaqueto, porém, as ombreiras se fazem presentes para autenticar o discurso do poder. Ao lado esquerdo da capa lê-se o enunciado “As Mulheres São Melhores, Mais Espertas e Mais Fortes Que Os Homens. A Ciência Garante". A imagem da modelo retoma uma imagem historicamente consagrada, a do imperador francês Napoleão Bonaparte ${ }^{10}$ :

8 Capa da revista Nova disponível em: <http://passarelacultural.blogspot.com.br/2011/12/sessaonostalgia_29.html>. Consulta em: 31 de Jan. de 2012.

${ }^{9}$ Disponível em:

$<$ https://www.assine.abril.com.br/portal/revista!initRevista.action?codProjeto=905\&origem=google11/Pe squisa_Web_Marca_Mulher_Nova\&campanha=B4CG\&gclid=CIDcj9_do64CFZFW7Aodwm19Pw >. Consulta em: 30 de Jan. 2012.

${ }^{10}$ Disponível em: http://educaterra.terra.com.br/voltaire/artigos/napoleao.htm Consulta em: 31/01/2012 


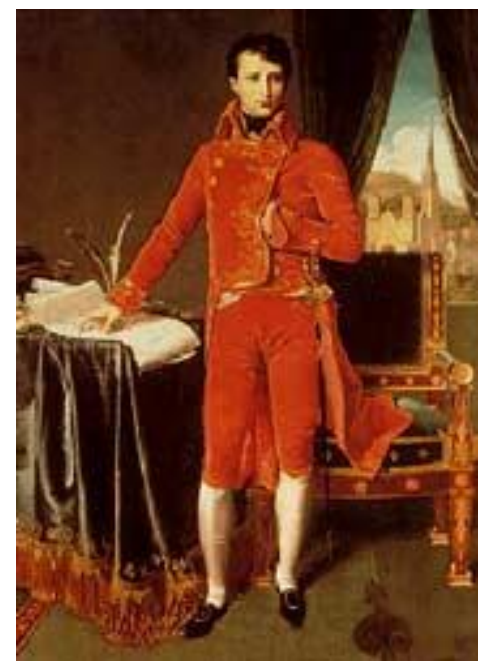

Figura 6: Napoleão Bonaparte por Jean Auguste Dominique Ingres, 1804

A mão da modelo posicionada por dentro do casaco, a cor e os bordados rememoram as pinturas representativas do importante líder político e militar francês, responsável por estabelecer a hegemonia francesa sobre a maior parte da Europa, constituindo-se, assim, como uma dos maiores símbolos de poder da história. O enunciado reitera a busca pela superioridade feminina, autenticando-a através da comprovação científica: "A Ciência Garante”, explicitamente declara "As Mulheres São Melhores, Mais Espertas e Mais Fortes Que Os Homens". Trata-se de uma retomada e, ao mesmo tempo da oposição, a um discurso já sabido, ainda que não mais enunciado explicitamente, segundo o qual essas características seriam antes atribuídas repetida e exclusivamente aos homens.

Observa-se, portanto, a construção de um discurso segundo uma formação discursiva outra e antagônica em relação àquela que se poderia designar como 'patriarcal', senão 'machista', em especial se considerarmos que o discurso, manifesto sob a forma de enunciados, origina-se de acordo com uma dada formação discursiva que lhe orienta o modo como é enunciado e também a compreensão do que é dito. Para Pêcheux (1995) a formação discursiva diz respeito a um conjunto finito e delimitado de discursos efetivamente enunciados sobre um determinado tema, assumindo em relação a esse tema um posicionamento específico:

Chamaremos, então, formação discursiva aquilo que, em uma formação ideológica dada, isto é, a partir de uma posição dada em uma conjuntura dada, determinada pelo estado da luta de classes, determina "o que pode e o que deve ser dito" (articulado sob a forma de uma alocução, de um sermão, de um panfleto, de uma exposição, de um programa, etc.) (PÊCHEUX, 1995, p.160). 
A segunda imagem, que manifesta essa relação histórica, portanto discursiva, presente nos usos de um objeto que redimensiona o corpo feminino e lhe transfere certos atributos simbólicos masculinos, pertence a uma matéria da revista Manchete do ano de $1986^{11}$ :

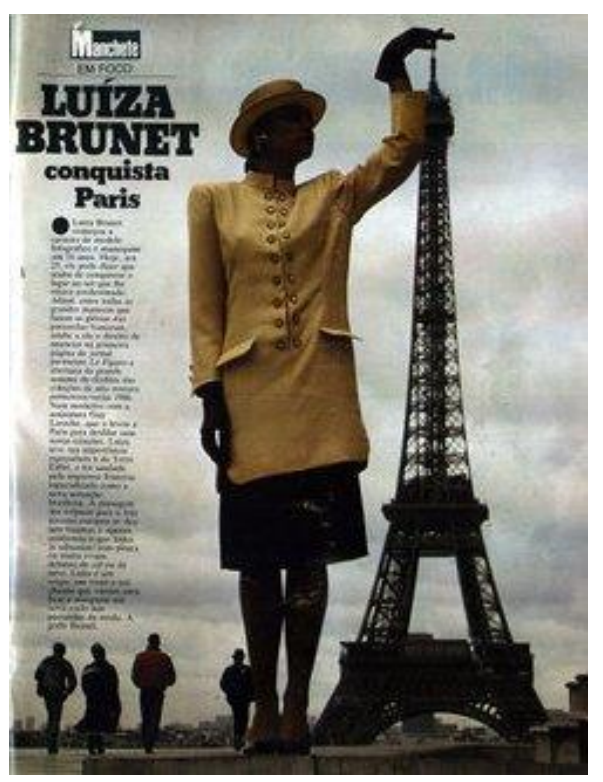

Figura 7: Revista Manchete, 1986

$\mathrm{Na}$ imagem, a modelo Luiza Brunet é fotografada vestindo roupa com ombreiras bem acentuadas, e com um efeito de ilusão de ótica, é captada pela câmera do mesmo tamanho da Torre Eiffel, o símbolo mais proeminente de Paris e da França ${ }^{12}$. No enunciado verbal lê-se "Luiza Brunet conquista Paris". A utilização do termo "conquistar" retoma enunciados cristalizados referentes à conquista da Alemanha nazista da cidade francesa: "Antes de conquistar Paris, as tropas alemãs [...]" "Hitler preparava a conquista da França[...]"14. O poder do chefe de estado alemão, Adolf Hitler, durante a Segunda Guerra Mundial, conquistador de territórios de grande parte da Europa e ainda um líder militar, é retomado pelo enunciado e, ainda, pela imagem da matéria, que posiciona a modelo de maneira que se equipare ao tamanho do monumento que toca, claramente o submetendo ao seu jugo. Ainda aparecem na imagem homens também fotografados de maneira com que pareçam menores e a seus pés, trazendo para a relação imagem/enunciado verbal outro significado: a sedução, a

\footnotetext{
${ }^{11}$ Imagem da revista Manchete disponível em: <static.uncyc.org/wiki/Revista_Manchete>. Consulta em: 31 de Jan. de 2012.

${ }^{12}$ Disponível em: <http://pt.wikipedia.org/wiki/Torre_Eiffel>. Consulta em: 31 de Jan. de 2012.

${ }^{13}$ Disponível em: <http://www.algosobre.com.br/historia/segunda-guerra-mundial-a.html>. Consulta em 12 de Jan. 2012.

${ }^{14}$ Disponível em: <http://www.tribunadaimprensa.com.br/?p=3046>. Consulta em 12 de Jan. 2012.
} 
conquista. Representa-se assim uma mulher sedutora, posando para um editorial de moda de uma revista, 'empoderada', engrandecida, no que concerne na arte de conquistar os homens. Assim, o poder a que se refere esse tipo de mídia é aquele relativo à capacidade de conquista do sexo oposto, reiterando assim a ambiguidade nessa forma de demonstração do poder em relação ao outro: ser poderosa para ser de alguém.

A terceira imagem, reproduzida abaixo, refere-se à capa da revista Manequim de julho de 1986:

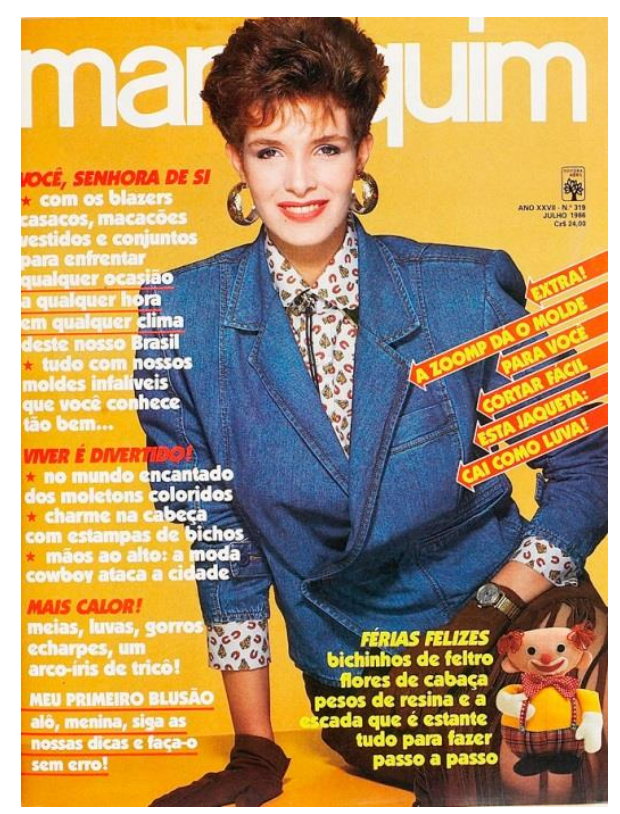

Figura 8: Revista Manequim, julho de 1986

Na imagem ${ }^{15}$, da revista voltada para a divulgação de moldes para a confecção de roupas em casa, a modelo usa um blazer em jeans, um tecido ligado ao trabalho desde suas origens, usado por mineradores do Oeste americano ${ }^{16}$, com ombreiras protuberantes. Do lado esquerdo da capa, ao alto, lemos: "Você, senhora de si”, um enunciado que rememora palavras de ordem da luta pela emancipação feminina, como a autonomia feminina frente ao domínio masculino, a liberdade e a mulher como dona de seu próprio corpo:

\footnotetext{
${ }^{15}$ Disponível em: <http://www.flickriver.com/photos/52190460@N03/tags/1986/>. Consulta em 31 de Jan 2012.

${ }^{16}$ Disponível em: <http://www.portaisdamoda.com.br/noticiaInt id 17825 n a+historia+do+jeans.htm>. Consulta em: 31 de Jan. 2012.
} 


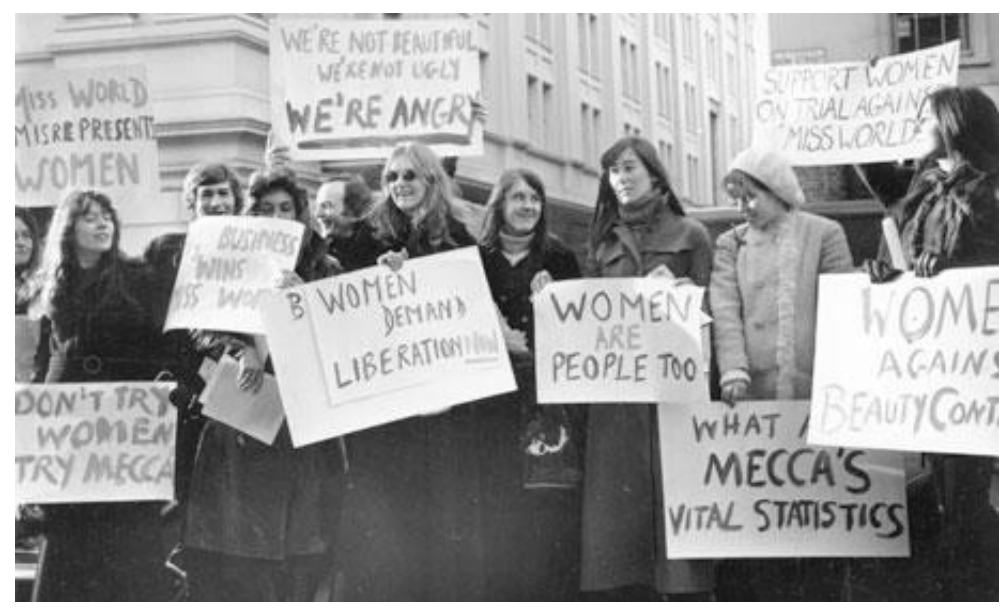

Figura 9: Passeata feminina do final da década de $60^{17}$

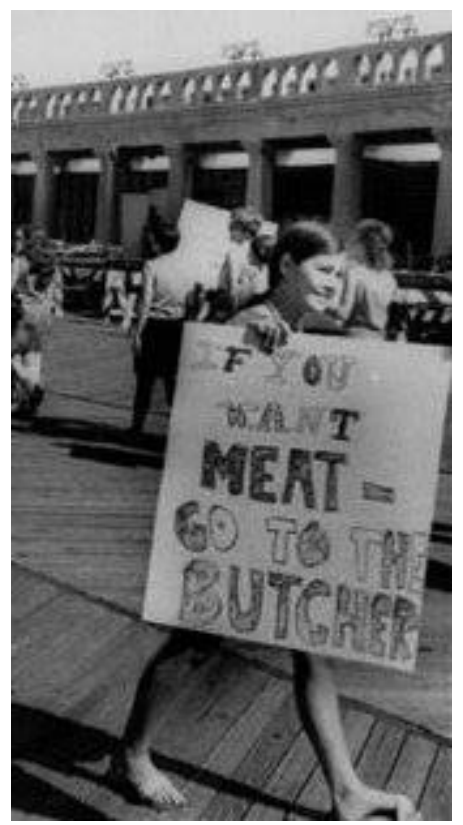

Figura 10: Passeata feminina do final da década de $60^{18}$

Combinada ao enunciado verbal, a fotografia da mulher com ombreiras autentica a posição feminina representada nessas revistas de moda que reiteram sua maior liberdade e o domínio de si e dos outros. As opções de moldes para roupas oferecidas pela revista, nesse período, em sua maioria, são roupas emprestadas do guarda roupa masculino: macacões, blazers, moda cowboy, o que também aponta para uma espécie de ambiguidade no direcionamento a um dado público leitor, a um dado segmento, uma vez que a revista fala com um tipo de mulher que é a que ainda fica em casa e costura

\footnotetext{
17 Disponível em: <http://artvistualculturemodernlifef09.blogspot.com.br/2010/11/different-ways-ofprotesting.html >. Consulta em: 31 de Jan. 2012.

${ }^{18}$ Disponível em: http://www.npr.org/templates/story/story.php?storyId=94240375 Consultada em: $31 / 01 / 12$
} 
suas próprias roupas. Para Courtine: "A sociedade democrática apaga os indícios físicos tradicionais, embaralha os velhos códigos da sociedade de ordem, banaliza a postura, mascara as hierarquias." (COURTINE, 2008, p.341). Esse embaralhamento, banalização e mascaramento talvez se explicasse nesse caso pela divisão de classes dos segmentos a que se dirigem essas revistas: por um lado, a consumidora das roupas prêt-à-porter, por outro, a consumidora que faz suas roupas ou que trabalho para as primeiras.

Ainda nos cabe apontar para uma provável contradição entre os enunciados dos cartazes do movimento feminista e as capas de revistas que, embora pareçam falar a mesma coisa em relação à necessidade de emancipação, de afirmação do poder feminino, de demonstração física desse poder por meio do corpo que a elas pertence, seus enunciados não significam a mesma coisa uma vez que não falam do mesmo lugar. O sentido de liberdade e poder para ambos os lugares de enunciação se distinguem, uma vez que nas revistas o poder está atrelado à sedução do sexo oposto e nos cartazes feministas o poder está relacionado à liberdade da mulher e à igualdade de gêneros.

\section{Considerações finais}

Através desta breve análise, buscou-se entender a ressignificação do corpo feminino, tido historicamente como frágil e delicado que, para infiltrar-se em um ambiente de predomínio masculino, precisava da atribuição de um novo sentido. Ao fazer uso das ombreiras, o corpo feminino recria-se: uma linha reta e prolongada na altura dos ombros atribui um novo significado para esse corpo, rememorando o formato corporal masculino, a virilidade e, consequentemente, o poder. Essa nova silhueta, se não possibilitou que a mulher se posicionasse de maneira mais efetiva em esferas sociais antes dominadas pelos homens, ao menos sinalizou essa mudança, permitindo às mesmas a autenticação de sua presença nestes lugares. Observamos também a ambiguidade muitas vezes presente na construção dos enunciados das capas das revistas que representaram essa mudança na concepção do corpo feminino, quando em muitas delas é apreensível ainda o atravessamento de discursos contraditórios sobre o papel social da mulher. Elas são livres, se vestem para trabalhar como homens, mas também para seduzi-los. Assim, cabe-nos retomar os questionamentos de Courtine 2008, p.12) ao final de sua introdução para o volume 3 de História do Corpo: “[...] é mais do que nunca necessário interrogar, experimentar o limite do humano: 'Meu corpo será sempre meu corpo? ", 


\section{Referências bibliográficas}

BAUDOT, François. 2002 Moda do Século. São Paulo: Cosac\&Naify.

COURTINE, Jean-Jacques. 2008. O corpo anormal: história e antropologia culturais da deformidade. In: CORBIN, Alain; COURTINE, Jean-Jacques; VIGARELLO, Georges. História do corpo: as mutações do olhar. O século XX. Petrópolis: Editora Vozes.

1995. Os Stakhanovistas do Narcisismo: Body-building e puritanismo ostentatório na cultura americana do corpo. In: SANT'ANNA, Denise Bernuzzi de (org.). Políticas do corpo: elementos para uma história das práticas corporais. São Paulo: Estação Liberdade.

KÖHLER, Carl. 1983. História do vestuário. São Paulo: Martins Fontes.

LAVER, James. 1989. A Roupa e a Moda: uma história concisa. São Paulo: Companhia das Letras, 1989.

LE BRETON, David. 1995. A síndrome de Frankenstein. In: SANT'ANNA, Denise Bernuzzi de (org.) Políticas do corpo. São Paulo: Estação Liberdade.

LURIE, Alison. 1997. A linguagem das roupas. Rio de Janeiro: Rocco, 1997.

PÊCHEUX, M. 1995. Semântica e discurso: uma crítica à afirmação do óbvio. Campinas/SP: Editora da UNICAMP.

PIOVEZANI, Carlos. 2009. Foucault com Courtine: corpo e discurso. In: GOMES, Daniel; SOUZA, Pedro (org.). Foucault com outros nomes: lugares de enunciação. Ponta Grossa: Editora UEPG.

SCHILDER, Paul. 1980. A imagem do corpo: as energias construtivas da psique. São Paulo: Martins Fontes.

VEILLON, Dominique. 2004. Moda e Guerra - Um retrato da França ocupada. Rio de Janeiro: Jorge Zahar Editor.

VALCÁRCEL, Amélia. 1998. La memoria colectiva y los retos del feminismo. In VALCÁRCEL, A.; DOLORS, R. y ROSALÍA, R. (eds.): Los desafíos del feminismo ante el siglo XXI. Sevilla: Hypatia, Instituto Andaluz de la Mujer.

WEEKS, Jeffrey. 20000. O corpo e a sexualidade. In: LOURO, Guacira Lopes. (Org.). O corpo educado: pedagogias da sexualidade. Belo Horizonte: Autêntica. 
Para citar essa obra:

PEREZ, Leonardo; CURCINO, Luzmara. Construindo ombros fortes: a roupa ressignificando o corpo feminino. In: RUA [online]. 2014, no. 20. Volume 1 - ISSN 1413-2109. Consultada no Portal Labeurb - Revista do Laboratório de Estudos Urbanos do Núcleo de Desenvolvimento da Criatividade.

http://www.labeurb.unicamp.br/rua/

Capa: MUGLER, Thierry. 1986/87. Les Meilteuses. Disponível em: http://thierrymugler.tumblr.com/post/72069682001/thierry-mugler-les-milteusescommunist-style

\section{Laboratório de Estudos Urbanos - LABEURB}

Núcleo de Desenvolvimento da Criatividade - NUDECRI

Universidade Estadual de Campinas - UNICAMP

http://www.labeurb.unicamp.br/

\section{Endereço:}

LABEURB - LABORATÓRIO DE ESTUDOS URBANOS

UNICAMP/COCEN / NUDECRI

CAIXA POSTAL 6166

Campinas/SP - Brasil

CEP 13083-892

Fone/ Fax: (19) 3521-7900

Contato: http://www.labeurb.unicamp.br/contato 